Acta Crystallographica Section C

Crystal Structure

Communications

ISSN 0108-2701

\section{Escitalopram oxalate: co-existence of oxalate dianions and oxalic acid molecules in the same crystal}

\author{
William T. A. Harrison, ${ }^{a *}$ H. S. Yathirajan, ${ }^{b}$ S. Bindya, ${ }^{b}$ \\ H. G. Anilkumar ${ }^{b}$ and Devaraju ${ }^{b}$ \\ ${ }^{a}$ Department of Chemistry, University of Aberdeen, Meston Walk, Aberdeen AB24 \\ 3UE, Scotland, and ${ }^{\mathbf{b}}$ Department of Studies in Chemistry, University of Mysore, \\ Manasagangotri, Mysore 570 006, India \\ Correspondence e-mail: w.harrison@abdn.ac.uk
}

Received 18 December 2006

Accepted 19 December 2006

Online 23 January 2007

The title compound \{systematic name: $(+)-(S)-3-[5-c y a n o-2-$ (4-fluorophenyl)-1,3-dihydroisobenzofuran-2yl]propanaminium oxalate oxalic acid 0.325 -hydrate\}, $2 \mathrm{C}_{20} \mathrm{H}_{22} \mathrm{FN}_{2} \mathrm{O}^{+} \cdot \mathrm{C}_{2} \mathrm{O}_{4}{ }^{2-}$.$\mathrm{C}_{2} \mathrm{H}_{2} \mathrm{O}_{4} \cdot 0.325 \mathrm{H}_{2} \mathrm{O}$, is a molecular salt of the $\mathrm{N}$-protonated escitalopram cation. As well as charge-balancing oxalate dianions, neutral molecules of oxalic acid are present. The component species interact by way of $\mathrm{N}-\mathrm{H} \cdots \mathrm{O}$ and short
$\mathrm{O}-\mathrm{H} \cdots \mathrm{O}$ hydrogen bonds, resulting in supramolecular chains.

\section{Comment}

(+)-(S)-1-[3-(Dimethylammonio)propyl]-1-(4-fluorophenyl)-5phthalan-5-carbonitrile oxalate $\left(\mathrm{C}_{20} \mathrm{H}_{21} \mathrm{FN}_{2} \mathrm{O}\right)$, common names escitalopram or $S$-(+)-citalopram, is a widely prescribed drug used to treat depression and related conditions (Burke, 2002). It is conveniently introduced as an oxalate salt, with a nominal formula usually given as $\mathrm{C}_{20} \mathrm{H}_{21} \mathrm{FN}_{2} \mathrm{O} \cdot \mathrm{C}_{2} \mathrm{H}_{2} \mathrm{O}_{4}$, i.e. the presumed proton-transfer reaction is not specified (Sorbera et al., 2001). As part of our ongoing crystallographic studies of pharmaceutical molecules (Harrison et al., 2005), we now report the structure of the title compound, (I), in which two N-protonated escitalopram cations $\left(\mathrm{C}_{20} \mathrm{H}_{22} \mathrm{FN}_{2} \mathrm{O}^{+}\right)$and a $\mathrm{C}_{2} \mathrm{O}_{4}{ }^{2-}$ oxalate dianon are accompanied by a neutral molecule of oxalic acid and a partially occupied water molecule (Fig. 1).

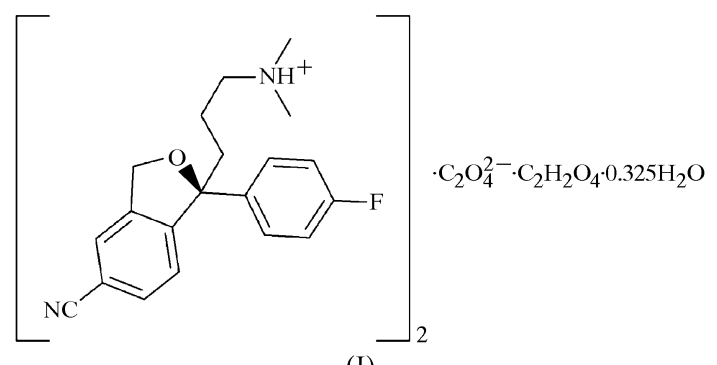

(I)

The bond lengths and angles in (I) fall within their expected ranges (Cambridge Structural Database, Version 5.27; Allen,

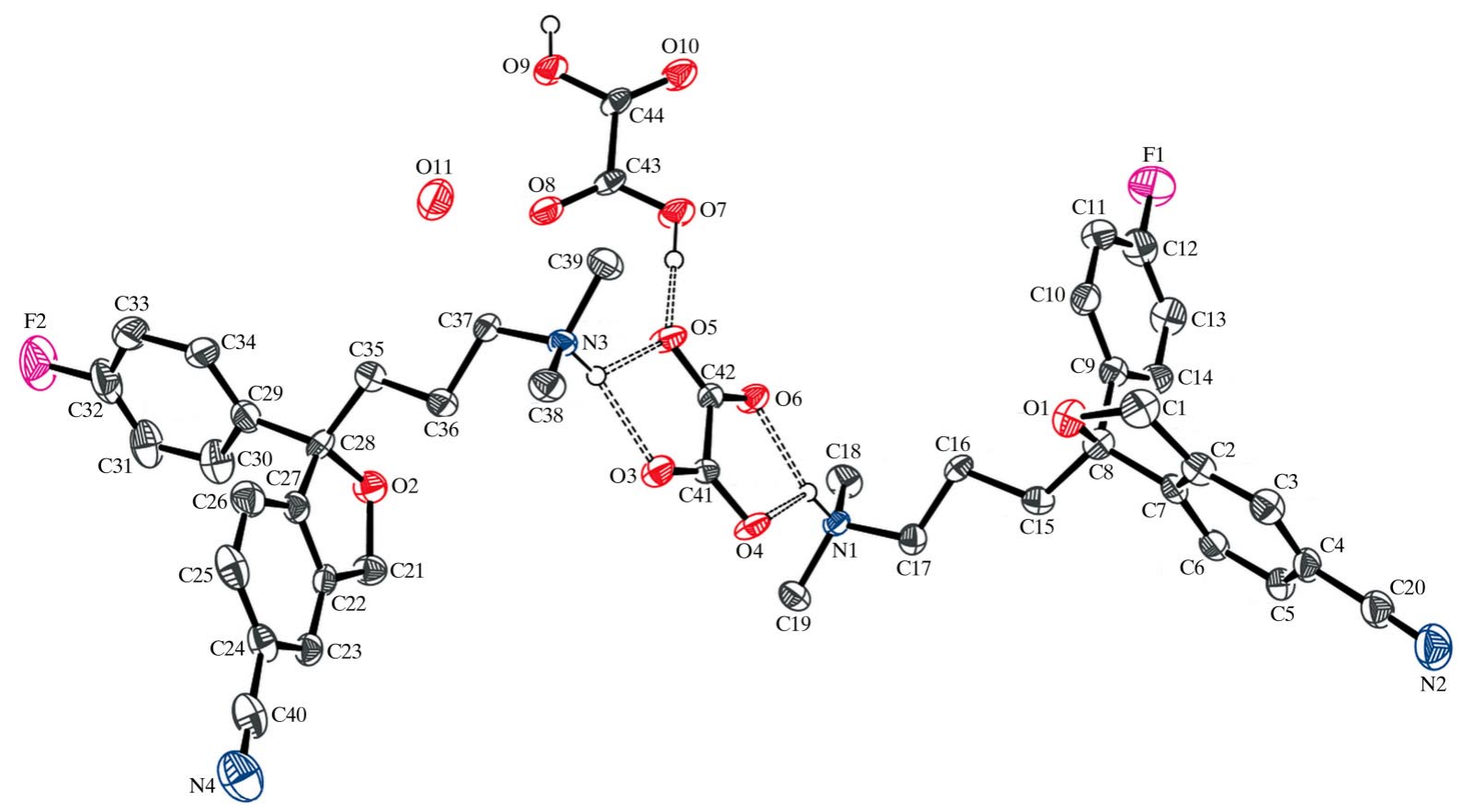

Figure 1

The molecular structure of (I), showing 50\% probability displacement ellipsoids (arbitrary spheres for $\mathrm{H}$ atoms). All $\mathrm{H}$ atoms, except those involved in hydrogen bonds (dashed lines), have been omitted for clarity. 
2002). There are two $\mathrm{C}_{20} \mathrm{H}_{22} \mathrm{FN}_{2} \mathrm{O}^{+}$cations in the asymmetric unit; atoms $\mathrm{C} 8$ and $\mathrm{C} 28$ are assumed to possess $S$ configurations, consistent with the known absolute structure of the biologically active enantiomer of citalopram (Sanchez et al., 2004). For the C1-containing molecule, the dihedral angle between the mean planes of the $\mathrm{C} 2-\mathrm{C} 7$ and $\mathrm{C} 9-\mathrm{C} 14$ benzene rings is $62.83(13)^{\circ}$, and the $\mathrm{C} 1 / \mathrm{C} 2 / \mathrm{C} 7 / \mathrm{C} 8 / \mathrm{O} 1$ five-membered ring displays an envelope conformation with atom $\mathrm{O} 1$ in the flap position [the displacement from the $\mathrm{C}$-atom mean plane is 0.435 (5) $\AA$ ]. In the $\mathrm{C} 21$-containing molecule, the dihedral angle between the $\mathrm{C} 22-\mathrm{C} 27$ and $\mathrm{C} 29-\mathrm{C} 34$ mean planes is $81.99(13)^{\circ}$, and the envelope conformation for $\mathrm{C} 21 / \mathrm{C} 22 / \mathrm{C} 27 /$ $\mathrm{C} 28 / \mathrm{O} 2$ is less pronounced, with atom $\mathrm{O} 2$ displaced from the C-atom mean plane by 0.113 (6) $\AA$. The oxalate species are both approximately planar; the dihedral angle between the $\mathrm{C} 41 / \mathrm{O} 3 / \mathrm{O} 4$ and $\mathrm{C} 42 / \mathrm{O} 5 / \mathrm{O} 6$ groupings is $4.4(3)^{\circ}$, and the equivalent value for $\mathrm{C} 43 / \mathrm{O} 7 / \mathrm{O} 8$ and $\mathrm{C} 44 / \mathrm{O} 9 / \mathrm{O} 10$ is $2.8(6)^{\circ}$.

The component species in (I) interact by way of $\mathrm{N}-\mathrm{H} \cdots \mathrm{O}$ and $\mathrm{O}-\mathrm{H} \cdots \mathrm{O}$ hydrogen bonds (Table 1), such that both $\mathrm{C}_{20} \mathrm{H}_{22} \mathrm{FN}_{2} \mathrm{O}^{+}$cations make bifurcated $\mathrm{N}-\mathrm{H} \cdots(\mathrm{O}, \mathrm{O})$ hydrogen bonds to the same oxalate dianion. Then, the $2 \mathrm{C}_{20} \mathrm{H}_{22} \mathrm{FN}_{2} \mathrm{O}^{+} \cdot \mathrm{C}_{2} \mathrm{O}_{4}{ }^{2-}$ units are linked into [001] chains by way of the oxalic acid molecules, i.e. the oxalate dianions and oxalic acid molecules alternate in the chains (Fig. 2). The short $\mathrm{H}$... O separations of the oxalic acid-to-oxalate hydrogen bonds suggests that they are strong interactions.

Although it is not expected from a consideration of the $\mathrm{p} K_{a}$ values of oxalic acid ( $\mathrm{p} K_{a 1}=1.23$ and $\mathrm{p} K_{a 2}=4.19 ;$ Newkome $e t$ $a l ., 1985)$ the co-existence of oxalate dianions and oxalic acid molecules in the same crystal has been observed in a number of compounds, three examples being bis(pyridinium) oxalate oxalic acid (Newkome et al., 1985), barium oxalate oxalic acid dihydrate (Chaix-Pluchery et al., 1989) and 1- $(\alpha$-pyrrolidiniobenzyl)-2-naphthol oxalate oxalic acid (Periasamy et al., 2004). These three compounds show the same alternating oxalate-oxalic acid hydrogen-bonded chains seen in (I).

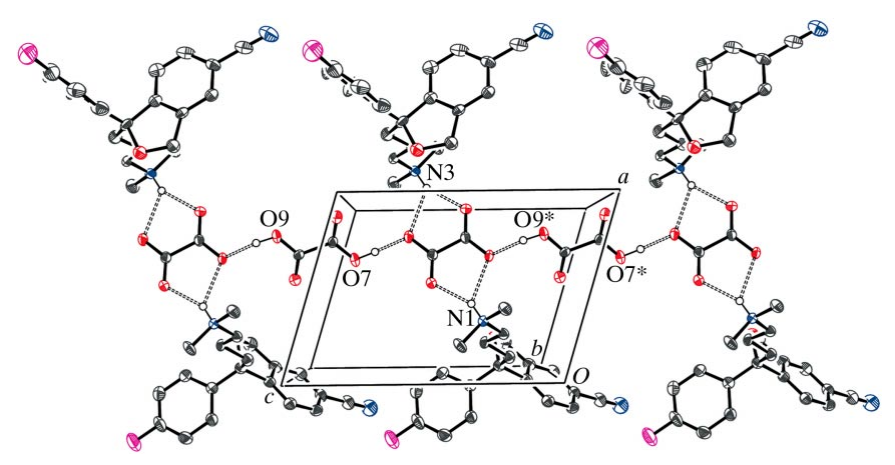

Figure 2

A view along [010] of part of an [001] chain in (I), with hydrogen bonds shown as dashed lines. Atoms labelled with an asterisk $(*)$ are generated by the symmetry operation $(x, y, z-1)$.

\section{Experimental}

The title compound was obtained as a gift sample from Jubilant Organosys, Nanjangud, India. The sample of (I) was recrystallized from ethanol (m.p. $420 \mathrm{~K}$ ).

Crystal data

$2 \mathrm{C}_{20} \mathrm{H}_{22} \mathrm{FN}_{2} \mathrm{O}^{+} \cdot \mathrm{C}_{2} \mathrm{O}_{4}{ }^{2-} \cdot \mathrm{C}_{2} \mathrm{H}_{2} \mathrm{O}_{4} \cdot-$ $0.325 \mathrm{H}_{2} \mathrm{O}$

$M_{r}=834.05$

Monoclinic, $P 2_{1}$

$a=7.9355(3) \AA$

$b=24.7376(9) \AA$

$c=11.1332(5) \AA$

$\beta=106.589(2)^{\circ}$

$$
\begin{aligned}
& V=2094.54(14) \AA^{3} \\
& Z=2 \\
& D_{x}=1.324 \mathrm{Mg} \mathrm{m}^{-3} \\
& \text { Mo } K \alpha \text { radiation } \\
& \mu=0.10 \mathrm{~mm}^{-1} \\
& T=120(2) \mathrm{K} \\
& \text { Block, colourless } \\
& 0.32 \times 0.24 \times 0.18 \mathrm{~mm}
\end{aligned}
$$

\section{Data collection}

Nonius KappaCCD diffractometer $\omega$ and $\varphi$ scans

Absorption correction: multi-scan (SADABS; Bruker, 2003)

$T_{\min }=0.969, T_{\max }=0.982$

7581 measured reflections 3609 independent reflections 2652 reflections with $I>2 \sigma(I)$ $R_{\text {int }}=0.037$

$\theta_{\max }=25.5^{\circ}$

\section{Refinement}

Refinement on $F^{2}$

$R\left[F^{2}>2 \sigma\left(F^{2}\right)\right]=0.042$

$w R\left(F^{2}\right)=0.095$

$S=1.02$

\begin{tabular}{|c|c|c|c|c|}
\hline$D-\mathrm{H} \cdots A$ & $D-\mathrm{H}$ & $\mathrm{H} \cdots A$ & $D \cdots A$ & $D-\mathrm{H} \cdots A$ \\
\hline $\mathrm{N} 1-\mathrm{H} 1 \ldots \mathrm{O} 6$ & 0.93 & 1.91 & $2.768(4)$ & 152 \\
\hline $\mathrm{N} 1-\mathrm{H} 1 \cdots \mathrm{O} 4$ & 0.93 & 2.22 & $2.886(4)$ & 128 \\
\hline $\mathrm{N} 3-\mathrm{H} 2 \cdots \mathrm{O} 3$ & 0.93 & 1.91 & $2.764(4)$ & 152 \\
\hline $\mathrm{N} 3-\mathrm{H} 2 \cdots \mathrm{O} 5$ & 0.93 & 2.22 & $2.884(4)$ & 127 \\
\hline $\mathrm{O} 7-\mathrm{H} 3 \cdots \mathrm{O} 5$ & $0.91(3)$ & $1.56(3)$ & $2.466(4)$ & $177(4)$ \\
\hline $\mathrm{O} 9-\mathrm{H} 4 \cdots \mathrm{O} 4^{\mathrm{i}}$ & $0.91(3)$ & $1.57(3)$ & $2.465(4)$ & $173(4)$ \\
\hline
\end{tabular}

3609 reflections

562 parameters

$\mathrm{H}$ atoms treated by a mixture of independent and constrained refinement

Table 1

Hydrogen-bond geometry $\left(\AA{ }^{\circ}\right)$.

Symmetry code: (i) $x, y, z+1$.

Anomalous dispersion effects were negligible and Friedel pairs were merged before refinement. The absolute structure of (I) was assigned on the basis of the known chirality of escitalopram (Sanchez et al., 2004). The $\mathrm{C}$ - and $\mathrm{N}$-bound $\mathrm{H}$ atoms were placed in idealized locations $(\mathrm{C}-\mathrm{H}=0.95-0.99 \AA$ and $\mathrm{N}-\mathrm{H}=0.93 \AA)$ and refined as riding with $U_{\text {iso }}(\mathrm{H})$ values of $1.2 U_{\text {eq }}$ (carrier) or $1.5 U_{\text {eq }}$ (methyl C). The oxalic acid $\mathrm{H}$ atoms were located in a difference map and refined with the restraint $\mathrm{O}-\mathrm{H}=0.90(1) \AA$ and the constraint $U_{\text {iso }}(\mathrm{H})=$ $1.2 U_{\text {eq }}(\mathrm{O})$. The $\mathrm{H}$ atoms of the partially occupied water molecule could not be located.

Data collection: COLLECT (Nonius, 1998); cell refinement: SCALEPACK (Otwinowski \& Minor, 1997); data reduction: SCALEPACK and DENZO (Otwinowski \& Minor, 1997), and SORTAV (Blessing, 1995); program(s) used to solve structure: SHELXS97 (Sheldrick, 1997); program(s) used to refine structure: SHELXL97 (Sheldrick, 1997); molecular graphics: ORTEP-3 (Farrugia, 1997); software used to prepare material for publication: SHELXL97.

We thank the EPSRC National Crystallography Service (University of Southampton) for data collection. 
Supplementary data for this paper are available from the IUCr electronic archives (Reference: GD3075). Services for accessing these data are described at the back of the journal.

\section{References}

Allen, F. H. (2002). Acta Cryst. B58, 380-388.

Blessing, R. H. (1995). Acta Cryst. A51, 33-38.

Bruker (2003). SADABS. Bruker AXS Inc., Madison, Wisconsin, USA.

Burke, W. J. (2002). Expert Opin. Invest. Drugs, 11, 1477-1486.

Chaix-Pluchery, O., Mutin, J. C., Bouillot, J. \& Niepce, J. C. (1989). Acta Cryst. C45, 1699-1705.

Farrugia, L. J. (1997). J. Appl. Cryst. 30, 565.
Harrison, W. T. A., Yathirajan, H. S., Anilkumar, H. G., Sarojini, B. K., Narayana, B. \& Lobo, K. G. (2005). Acta Cryst. E61, o3810-o3812.

Newkome, G. R., Theriot, K. J. \& Fronczek, F. R. (1985). Acta Cryst. C41, $1642-1644$

Nonius (1998). COLLECT. Nonius BV, Delft, The Netherlands.

Otwinowski, Z. \& Minor, W. (1997). Methods in Enzymology, Vol. 276, Macromolecular Crystallography, Part A, edited by C. W. Carter Jr \& R. M. Sweet, pp. 307-326. New York: Academic Press.

Periasamy, M., Reddy, M. N. \& Anwar, S. (2004). Tetrahedron Asymmetry, 15, 1809-1812.

Sanchez, C., Bogeso, K. P., Ebert, B., Reines, E. H. \& Braestrup, C. (2004). Psychopharmacology, 174, 163-176.

Sheldrick, G. M. (1997). SHELXS97 and SHELXL97. University of Göttingen, Germany.

Sorbera, L. A., Revel, L., Martin, L. \& Castaner, J. (2001). Drugs Future, 26, $115-120$ 